\title{
DEVELOPMENT OF THERAPEUTIC ATTITUDES: ATTITUDES OF TRAINEES IN TRAINING
}

\author{
Barbara Pastner, MA \\ Johanna Alexopoulos, PhD \\ Christine Rohm, MA \\ Ingrid Preusche, PhD \\ Henriette Loeffler-Stastka, MD \\ Medical University Vienna
}

\begin{abstract}
Address for correspondence:
Assoc. Prof. Priv. Doz. Dr. Henriette Loeffler-Stastka

Medical University Vienna, Dept. of Psychoanalysis and Psychotherapy, Waehringer Guertel 18-20, A-1090 Vienna, Austria
\end{abstract}

\begin{abstract}
Objectives: Therapeutic attitudes of trainees were identified and a possible relation between the therapeutic attitudes and the interpersonal problems of the trainees were examined. Therapeutic attitudes and the emotional reaction (countertransference) of the trainees to a standardized patient and the trainees' ratings of the therapeutic relationship and the trainees rating of affect experience and affect regulation of the standardized patient were also related to each other.

Methods: A random group of trainees of the psychotherapeutic propaedeutic $(n=59)$ was investigated. In the course of this training standardized patients had to be explored. The measurements used are the questionnaire for therapeutic attitudes (TASC 2), the questionnaire for interpersonal problems (IIP), the emotional response questionnaire (CTQ), the questionnaire for psychotherapeutic relationship (PRQ), and the questionnaire for affect perception and affect regulation (AREQ-K). To assess the relation between therapeutic attitudes and the reaction of the therapist to the standardized patient, the TASC 2 scores were analyzed in relation to the ratings in all the other questionnaires using Pearson correlation coefficients.
\end{abstract}


Results: Therapeutic attitudes of the (future) therapist and his or her emotional response towards the patient were interrelated. The trainees' evaluation of the emotional response is associated with his or her therapeutic attitudes and reflects patient-induced countertransference reactions.

Conclusion: The results indicate that trainees' self-perceptions are related to patient-perceptions. This leads to the conclusion that (future) therapist's selfreported attitudes are of considerable value in understanding how individual therapists contribute to the therapeutic process.

Keywords: Countertransference, psychotherapeutic attitudes, standardized patient, trainees, psychotherapy training

\section{Introduction}

Understanding the modes of operation of therapeutic training is of high relevance regarding the optimization of training outcome and even more so in the context of psychotherapy research in general. Nevertheless, up to now research in the field of therapeutic training was more or less neglected (Rønnestad \& Ladany, 2006) and existing studies almost exclusively focused on skill achievement as a measure of outcome (Taubner, Kächele, Visbeck, Rapp, \& Sandell, 2010). Though, measuring skill achievement is certainly a valuable approach it yet poses some limitations. For instance, therapists who were trained in the same theoretical orientation and who achieved the same therapeutic skills do produce significantly different outcomes (Luborsky et al., 1986; Shaw et al., 1999). Thus, there must be some further variable that additionally influences the training outcome.

Beutler and colleagues (2004) introduced the therapist variable. Hence, the influence of inferred states - like the therapist's personality and his or her therapeutic attitude - is to be considered as a crucial element in the therapeutic process. Coming to think about the sparseness of literature in this area of research, the renewed interest in this topic seems inevitable.

Following the work of Ronnestad and Skovholt (2003), who proposed a model of professional development in the field of psychotherapy on several dimensions, not only the simple acquisition of skills is considered, but also the personal changes the trainees undergo. According to the tripartite model of psychotherapy training - incorporating personal therapy, supervision, and skill achievement (Orlinsky \& Rønnestad, 2005) - the training itself, besides the achievement of theoretical skills, contributes to personal development and fosters personal change. By offering the possibility of self-development in personal qualities required to be an effective therapist, skills training not only enhances performance but also facilitates the personal development of the trainee. This is of high importance considering that choosing a career in the psychotherapeutic field demands much of personal resources, thus, 
placing emphasis on the capability for self-knowledge and self-care appears to be inevitable. However, it is still unclear how these personal changes can be identified and how skill achievement can best act as a sort of supplement to the other parts of therapeutic training (Pascual-Leone, Rodriguez-Rubio, \& Metler, 2013).

One possibility to convey theoretical knowledge as well as personal experience to students is the training with standardized patients (SPs, Brenner, 2009). SPs are trained actors who are deployed to assist health care providers in various types of clinical encounters for the purposes of training and evaluation (Weaver \& Erby, 2012). Trainings with SPs have a long tradition in medical curricula most often applied as a tool for training clinicians in medical skills like conducting physical exams or taking up medical histories. More recently SPs have been increasingly used to assist in the development and assessment of psychosocial skills, including those related to patient-centered communication and relationship building (LongBellil et al., 2011). In order to provide students with the possibility to experience their personal strengths and weaknesses in working with a patient, training with SPs is incorporated in the curriculum of the Medical University of Vienna and in curriculum of the basic psychotherapeutic training program of the University of Vienna. In various lectures psychiatrists or other qualified experts (e.g. psychologists, psychotherapists, and psychoanalysts) operate together with actors trained on role scripts written by those experts. The various scripts display different types of disorders and pathologies (e.g. depression with suicidal tendency, somatoform disorder, anxiety and panic disorder). However, all role scripts that actors are trained on share the same level of psychic structure namely borderline personality organization and thus demonstrate defensive mechanisms of splitting, projective identification, idealization, as well as devaluation (Kernberg, 1993).

During the course of the training trainees conduct initial interviews with the SPs to gather information usable for a psychiatric diagnosis, for diagnosing the personality structure, as well as to encounter transference and countertransference phenomena. The didactic conversion is based on a feedback-slope, in which trainees reflect their experience in the interview with the SPs, enhancing (self-)perception and therapeutic attitudes.

Therapeutic attitudes derive from the personal background of the (future) therapist and offer the base on which the therapeutic process develops during the treatment (R. Sandell et al., 2004). The therapeutic attitudes are grounded on values and convictions of the (future) therapist, on his or her epistemological style of thinking and belief in the nature of human mind and psychotherapy (Rolf Sandell et al., 2006). Therapeutic attitudes contribute substantially to the explanation of variance of treatment outcome and are 
clearly associated with the personal attitudes and experiences of the (future) therapist (Rolf Sandell et al., 2007).

Thinking about the tripartite model, it is of interest how theoretical skill training could best serve as a complement to personal therapy and supervision. Not only personal therapy and supervision, especially skills training would benefit from considering the inferred states of trainees. Training with standardized patients offers a good combination to convey theoretical knowledge and personal experience. It therefore seems to offer one possibility to encourage trainees to reflect on their personal attitudes towards the patient and the presented theoretical and practical material. This fosters the development of therapeutic attitudes, as well as trainees' awareness for themselves. In order to investigate the influence of inferred states of trainees, especially their therapeutic attitudes, the relation between interpersonal problems and the therapeutic attitudes of trainees was investigated within training with SPs. Furthermore, it was of interest how the therapeutic attitudes relate to the trainee's ratings of the therapeutic relationship, as well as the trainee's rating of affect experience and affect regulation of the patient.

\section{Methods}

The study was conducted in accordance with the Declaration of Helsinki (1973, revised in 1983) and local guidelines and regulations of the Medical University of Vienna. The study protocol was approved by the Ethics Committee of the Medical University of Vienna. Written informed consent was obtained from the study participants after a complete description of the study.

\section{Participants}

The group of trainees investigated in this study participated in a basic psychotherapeutic training program (7 male, 52 female; mean age: $31.45 \pm$ 7.93, min 20, max 49 years). Of the trainees $10 \%$ completed studies at the Medical University Vienna, 32\% had a degree in psychology and $7 \%$ were trained as social workers. $51 \%$ did not state their profession. $56 \%$ reported to have self-experience regarding psychotherapeutic methods and interventions.

\section{Measures}

The assessment was structured as follows:

(a) A demographic questionnaire; measuring participants' age, gender, education, and level of self-experience.

(b) The therapeutic attitude (ThAt) questionnaire developed by Sandell, Carlsson, Schubert, Broberg, Lazar, \& Grant (2004) measures the attitudes and assumptions of psychotherapists in three dimensions 
(TASC-2 scales) displaying nine factors: curative components of psychotherapy (Adjustment, Insight, Kindness), attitudes toward psychotherapeutic approaches (Neutrality, Supportiveness, Selfdoubt), and basic assumptions and beliefs about psychotherapy (Irrationality, Artistry and Pessimism).

(c) The Inventory of Interpersonal Problems (IIP;Horowitz, Rosenberg, Baer, Ureño, \& Villaseñor, 1988) is based on the interpersonal circumplex model designed to evaluate persons' problems in relation to others. In this study the short version was used, which is a 64-item self-report questionnaire designed to provide a normed, psychometrically valid instrument for assessing problems associated with each octant of the interpersonal circumplex (IIP-C; Horowitz, Strauß \& Kordy, 2000).

(d) The Emotional Response Questionnaire, the former Countertransference Questionnaire (CTQ; Zittel \& Westen, 2003; German translation: Löffler-Stastka \& Grassl, 2006) is a 79-item clinician-report questionnaire for assessing countertransference patterns in psychotherapy, on the following dimensions: 1. overwhelmed/disorganized, 2. helpless/inadequate, 3. positive, 4. special/overinvolved, 5. sexualized, 6. disengaged, 7. parental/protective, 8. criticized/mistreated.

(e) The Psychotherapy Relationship Questionnaire (PRQ; Bradley, Heim, \& Westen, 2005) German translation: Löffler-Stastka, 2006) is a 90-item clinician-report questionnaire for assessing transference relationship patterns in psychotherapy. It provides five dimensions to describe these patterns: angry/entitled, anxious/preoccupied, secure/engaged, avoidant/counterdependent and sexualized.

(f) The Affect Experience and Affect Regulation Q-sort (Areq; Westen, Muderrisoglu, Fowler, Shedler, \& Koren, 1997) is used in the short version, which is a 27-item clinician-report questionnaire designed for assessing affect regulation and affect experience of a patient (AREQ-K; Loffler-Stastka \& Stigler, 2011). It yields three factors of affect experience: socialized negative effect (e.g. guilt), positive affect (e.g. interest), and intense negative effect (e.g. anger). Affect regulation dimension includes three factors: reality-focused response (e.g. goal-directed coping), externalizing defenses (e.g. projection), and avoidant defenses.

\section{Procedure}

Trainees participating in this study were assessed after the training with standardized patients incorporated in a basic psychotherapeutic training program (psychotherapeutic propaedeutic). Besides rating their therapeutic 
attitudes (TASC 2) and interpersonal problems (IIP) the group of trainees rated their emotional response (countertransference) towards the standardized patient (CTQ), the transference relationship pattern with this patient (PRQ) and the affect regulation and affect experience of this patient (AREQ - K).

\section{Statistics}

All statistical analyses were performed with IBM SPSS Statistics 19 software (IBM Corp., Armonk, NY, USA). For all analyses the significance threshold was set to $\mathrm{p} \leq 0.05$. To assess the inferred states of the trainees the relation between TASC 2 scores and IIP scores was examined. Furthermore, to assess the relation between inferred states of the trainees and their ratings of the standardized patient the TASC 2 scores were analyzed in relation to the ratings in the PRQ, CTQ and AREQ-K using Pearson correlation coefficients (using two-tailed significance levels).

\section{Results}

Therapeutic attitudes and interpersonal problems. Regarding therapeutic attitudes, trainees rated kindness $(\mathrm{M}=2.97, \mathrm{SD}=.68)$ higher as a curative factor in therapy than insight $(\mathrm{M}=2.76, \mathrm{SD}=.57)$, or adjustment $(\mathrm{M}=2.21, \mathrm{SD}=.49)$. Regarding therapeutic style factors, trainees rather focused on supportiveness $(\mathrm{M}=2.67, \mathrm{SD}=.48)$ than neutrality $(\mathrm{M}=2.60$, $\mathrm{SD}=.54)$ and showed a moderate amount of self-doubt $(\mathrm{M}=1.12, \mathrm{SD}=$ .63). Concerning their basic assumptions, trainees tended to believe that the human mind is rather rational (irrationality: $\mathrm{M}=2.10, \mathrm{SD}=.63$ ) and alterable (pessimism: $\mathrm{M}=2.75, \mathrm{SD}=.47$ ). Concerning the basic assumption of artistry $(\mathrm{M}=1.85, \mathrm{SD}=.59)$ trainees tended to consider psychotherapy more as a form of science compared to artistry. The standardized IIP scores demonstrated the main problems of the trainees according to the underlying circumplex scales. Trainees showed most difficulties regarding the scales overly exploitable (IIP-JK $=4.05, \mathrm{SD}=2.94$ ), overly nurturant (IIP-LM = $3.46, \mathrm{SD}=2.41)$, and overly subassertive $(\mathrm{IIP}-\mathrm{HI}=2.97, \mathrm{SD}=3.75)$. Regarding possible relations, for the curative factors of the TASC 2 a significant correlation with IIP scales for the scale adjustment and kindness was found. Trainees who reported to be less assertive believed that adjustment is less likely to be a curative factor $(r=-.432, p=.008)$, whereas those more vindictive and self-centered reported that kindness is a likely curative factor $(\mathrm{r}=.326, \mathrm{p}=.049)$. The therapeutic style did not correlate significantly with interpersonal problems. The basic assumption about the nature of psychotherapy and human mind again correlated with interpersonal problems. Participants who considered the human mind as more irrational are less socially inhibited $(\mathrm{r}=-.381, \mathrm{p}=.20)$ and more self-sacrificing $(\mathrm{r}=$ 
$.497, \mathrm{p}=.002)$. Furthermore, those trainees who considered psychotherapy to be a form of artistry compared to science are less domineering $(r=-.378$, $\mathrm{p}=.021)$ but to a higher extend socially inhibited $(\mathrm{r}=.452, \mathrm{p}=.005)$.

Therapeutic attitudes, countertransference, psychotherapeutic relationship, and affect. Adjustment as a curative factor correlated positively with positive affect and reality-focused affect in the AREQ-K and negatively with parental and protective countertransference. In contrast, in case insight was judged as an important curative factor the emotional response (countertransference) of the trainee was more parental and protective. No relations were found between the curative factors and the PRQ. Reality-focused affect (AREQ-K) was further related to the therapeutic style. Participants who were more supportive $(\mathrm{r}=.335, \mathrm{p}=.046)$ and those who reported more self-doubts $(\mathrm{r}=$ $.420, \mathrm{p}=.011$ ) judged the patients affect regulation as more reality-focused. Self-doubt was further correlated with a positive working alliance and positive, satisfying countertransference. Irrationality, as a basic assumption concerning the human mind, was associated with the patient experiencing socialized negative affect $(r=.373, p=.025)$ and the judgment of the therapeutic relationship as being more compliant $(\mathrm{r}=.345, \mathrm{p}=.043)$ and avoidant $(\mathrm{r}=.422, \mathrm{p}=.011)$. High scores on irrationality were further associated with a less positive, satisfying and more parental, protective countertransference. Similarly, Artistry was associated with less positive, satisfying and more parental, protective as well as helpless and inadequate countertransference. Finally, there was a positive correlation between intense, negative affect and pessimism $(r=.426, \mathrm{p}=.010)$. No other analysis reached the level of significance.

Table 1. Correlations between TASC 2 scales and Emotional Response Questionnaire scales (CTQ) of trainees $(n=59)$ 


\begin{tabular}{|c|c|c|c|c|c|c|c|c|}
\hline & $\begin{array}{c}\text { Hostile/ } \\
\text { mistreated }\end{array}$ & $\begin{array}{l}\text { Helpless/ } \\
\text { inadequate }\end{array}$ & $\begin{array}{l}\text { Positive/ } \\
\text { satisfying }\end{array}$ & $\begin{array}{l}\text { Parentall } \\
\text { protective }\end{array}$ & $\begin{array}{l}\text { Overw helmed/ } \\
\text { disorganized }\end{array}$ & $\begin{array}{l}\text { Special/over- } \\
\text { involved }\end{array}$ & Sexualized & Disengaged \\
\hline Adjustment & -0.137 & -0.191 & 0.317 & $-0.498^{*}$ & -0.201 & -0.014 & 0.349 & -0.323 \\
\hline Insight & 0.145 & 0.313 & -0.007 & $0.565^{\star \star}$ & 0.312 & 0.198 & 0.078 & 0.115 \\
\hline Kindness & -0.181 & -0.105 & 0.072 & 0.281 & -0.082 & -0.207 & 0.167 & -0.339 \\
\hline Neutrality & 0.135 & 0.058 & -0.207 & 0.201 & 0.042 & -0.077 & 0.197 & 0.142 \\
\hline $\begin{array}{l}\text { Supportivenes } \\
\mathrm{s}\end{array}$ & -0.128 & -0.278 & 0.105 & -0.22 & -0.2 & -0.059 & 0.398 & -0.257 \\
\hline Self-doubt & -0.01 & 0.11 & $0.521^{\star *}$ & 0.042 & 0.225 & 0.1 & 0.165 & 0.105 \\
\hline Irrationality & 0.036 & 0.362 & $-0.489^{*}$ & $0.533^{\text {** }}$ & 0.188 & 0.188 & -0.1 & 0.348 \\
\hline Art & 0.088 & $0.424^{*}$ & $-0.475^{*}$ & $0.49^{\star}$ & 0.113 & 0.028 & -0.261 & 0.215 \\
\hline Pessimism & -0.065 & -0.005 & -0.021 & 0.205 & 0.003 & -0.067 & 0.259 & 0.09 \\
\hline
\end{tabular}

\section{Discussion}

The aim of the present study was to identify the inferred states of the trainees, especially their psychotherapeutic attitudes, and to examine the relation between the psychotherapeutic attitudes and the emotional reaction (countertransference) of the trainee to a standardized patient, the trainees ratings of the psychotherapeutic relationship and the trainees rating of affect experience and affect regulation of the standardized patient. Analysis revealed that therapeutic attitudes of the (future) therapist and his or her emotional responses towards the patient are interrelated. The trainees' evaluation of the emotional response is associated with his or her therapeutic attitudes and reflects patient-induced countertransference reactions.

As already mentioned, the therapeutic attitudes and the emotional response of the trainee towards the patient and the therapeutic relationship are closely related. Though,this is the first study investigating therapeutic attitudes in relation to the patient, previous studies which focused on the emotional responses towards the patient reported similar results as were found in the present study (Heinonen et al., 2013; Rossberg, Karterud, Pedersen, \& Friis, 2007). For example, Colli (2013) demonstrated that the patient's pathologies are associated with consistent emotional response of the clinician. Furthermore, clinicians of different therapeutic approaches produce similar emotional responses, suggesting that patients ` pathologies are quite robust in evoking specific emotional responses. The results of the present study show that in association with the emotional responses there are two 
main attitudes emerging in the trainees while working with the standardized patient with borderline personality organization: First, trainees who are engaging in a rather parental, protective countertransference tend to rate adjustment as a less important curative component and emphasize the value of insight, irrationality and artistry. Second, trainees who are engaging in a rather positive, satisfying countertransference, tend to attribute the highest value to adjustment and supportiveness.

Interestingly, trainees' scores on a type of difficulty in practice called "Self-doubt" (denoting doubt about one's professional efficacy, Sandell 2004) were positively associated with a positive working alliance and positive, satisfying countertransference after an initial contact with a patient with borderline personality organization. This last result is in line with previous findings (Nissen-Lie, Monsen, \& Ronnestad, 2010) pointing at the positive influence of "Self-doubt" on the working alliance. Contemporary theoretical and clinical literature claims that countertransference reactions, the emotional responses of the therapist, are specific to patients' presenting concerns, interpersonal styles and underlying pathology (McIntyre \& Schwartz, 1998; Schwartz, Smith, \& Chopko, 2007). Clinical reaction related to the patient can profoundly affect psychotherapist perceptions of a patient's presenting concerns, symptom severity, and prognosis (Hayes \& Gelso, 2001). In particular patients with a borderline personality organization have been found to provoke intense emotional responses in the healthcare professional (Aviram, Brodsky, \& Stanley, 2006; Liebman \& Burnette, 2013; Salzer et al., 2013). Especially, but not only, for novice-trainees it seems challenging to rely on countertransferential reactions in diagnosing and working with a patient. For the purpose of training it therefore seems necessary to enable trainees to work with their personal feelings provoked by a patient. The results of the present study underline the importance of creating a possibility to get in touch with these feelings. This is in line with previous findings suggesting that clinicians can make diagnostic and therapeutic use of their responses to patients (Colli et al., 2013). Thus, personal feelings should not be judged as a confounding variable in the diagnostic and therapeutic process, but rather as a helpful contribution to professional development. Since self-doubt was associated with a positive working alliance and positive, satisfying countertransference, it could be positively interpreted as the willingness to get in touch with these personal countertransferential feelings. According to literature (Nissen-Lie, Monsen, Ulleberg, \& Rønnestad, 2013) the factor "self-doubt" is interpreted as reflecting a healthy self-critical evaluation and a humble attitude towards the complexities of therapeutic work. It refers to openness in questioning one's own personal experiences and in taking one's own unknown, conflicting affects into account. Training with standardized patients raises the possibility 
for experiencing oneself interacting with a patient and being confronted with the feelings provoked in this situation, this does not only promote performance enhancement, but fosters personal development of the (future) therapist. This form of training serves as a supplement to supervision keeping the tripartite model of psychotherapy training in mind. In the case of medical students the experiences gained in training with standardized patients incorporated in the medical curriculum could best serve as a first step towards the use of emotional responses and personal understanding in clinicians work and nurturing the therapeutic potential of the clinicianpatient-relationship. Training with standardized patients offers a preliminary stage in dealing with personal experiences to best be continued in intervision, supervision and Balint groups.

Leasure and colleagues (2013) already point out that in patientcentered professions it is common to prioritize the other's needs and goals over individual ones. As the results of the IIP demonstrate, trainees show difficulties being overly exploitable, nurturant and subassertive. As Laska and colleagues (2013) point out, these characteristics are in line with characteristics of effective therapists, showing flexible interpersonal style and the ability to develop a strong therapeutic alliance. It is eligible to suppose that these characteristics of the trainees, provide a possibility to develop functions like containment (Bion, 1962), and holding (Winnicott, 1989).

Taken together, the results indicate that certain trainee's selfperceptions, their therapeutic attitudes and emotional responses, are clearly related to patient-perceptions and lead to the conclusion that (future) therapist's self-reported attitudes can be of value in understanding how individual therapists contribute to the therapeutic process. In order to foster professional development of psychotherapy trainees and medical students it seems necessary to deliberate their personal experiences in concordance with skill achievement and to take their therapeutic attitudes into account.

Though, Taubner and colleagues (2010) claim that attitudes are established before the training in the therapeutic field (Taubner et al., 2010), the present study proposes that training can provide a framework in which the personal beliefs and assumptions can be made aware and can develop. As Carlsson and colleagues (2011) propose, training makes it possible to use the trainee's own value system in a more flexible way afterwards and thus to adjust to the clinical situation with a particular patient (Carlsson, Norberg, Schubert, \& Sandell, 2011) (Carlsson, Norberg, Schubert, \& Sandell, 2011).

\section{Limitations}

Since, the patients' affect experience and transference pattern was rated by the same trainee whose own countertransferential emotional 
response towards this patient was inquired, this might have been a source of measurement bias. Thus future research should apply a more rigorous research design including an independent assessment of the patient's characteristics or the use of an observer-rated analysis of trainee's reactions, or both. Furthermore, future should focus on the analysis at an item level of the questionnaires, to identify personal developmental processes in more detail.

\section{Acknowledgments}

This study is part of a project that received the Marianne-RinglerAward for Research in Psychotherapy. There is no conflict of interests.

\section{References:}

Aviram, R. B., Brodsky, B. S., \& Stanley, B. (2006). Borderline personality disorder, stigma, and treatment implications. Harvard Review of Psychiatry, 14(5), 249-256.

Beutler, L.E., Malik, M., Alimohamend, S., Harwood, T.M., Talebi, H., Noble, S., \& Wong, E. (2004). Therapist Variables. In M. J. Lambert (Ed.), Bergin and Garfield's handbook of psychotherapy and behavior change (Vol. 5). New York: Wiley.

Bion, WR. (1962). Learning from Experience London: Karnac: ASFAE. Brenner, A. M. (2009). Uses and limitations of simulated patients in psychiatric education. Acad Psychiatry, 33(2), 112-119. doi:

10.1176/appi.ap.33.2.112

Carlsson, Jan, Norberg, Joakim, Schubert, Johan, \& Sandell, Rolf. (2011). The development of therapeutic attitudes during and after psychotherapy training. European Journal of Psychotherapy \& Counselling, 13(3), 213-229. doi: 10.1080/13642537.2011.596722

Colli, A., Tanzilli, A., Dimaggio, G., \& Lingiardi, V. (2013). Patient Personality and Therapist Response: An Empirical Investigation. Am J Psychiatry. doi: 10.1176/appi.ajp.2013.13020224

Hayes, J. A., \& Gelso, C. J. (2001). Clinical implications of research on countertransference: Science informing practice. Journal of Clinical Psychology, 57(8), 1041-1051.

Heinonen, E., Lindfors, O., Harkanen, T., Virtala, E., Jaaskelainen, T., \& Knekt, P. (2013). Therapists' Professional and Personal Characteristics as Predictors of Working Alliance in Short-Term and Long-Term Psychotherapies. Clin Psychol Psychother. doi: 10.1002/cpp.1852 Horowitz, Leonard M., Rosenberg, Saul E., Baer, Barbara A., Ureño, Gilbert, \& Villaseñor, Valerie S. (1988). Inventory of interpersonal problems: Psychometric properties and clinical applications. J Consult Clin Psychol, 56(6), 885-892. doi: 10.1037/0022-006x.56.6.885 
Kernberg, O. F. (1993). Severe Personality Disorders: Psychotherapeutic Strategies: Yale University Press.

Laska, K. M., Smith, T. L., Wislocki, A. P., Minami, T., \& Wampold, B. E. (2013). Uniformity of evidence-based treatments in practice? Therapist effects in the delivery of cognitive processing therapy for PTSD. $J$ Couns Psychol, 60(1), 31-41. doi: 10.1037/a0031294

Leasure, E. L., Jones, R. R., Meade, L. B., Sanger, M. I., Thomas, K. G., Tilden, V. P., Warm, E. J. (2013). There is no "i" in teamwork in the patientcentered medical home: defining teamwork competencies for academic practice. Acad Med, 88(5), 585-592. doi: 10.1097/ACM.0b013e31828b0289 Liebman, R. E., \& Burnette, M. (2013). It's Not You, It's Me: An Examination of Clinician- and Client-Level Influences on Countertransference Toward Borderline Personality Disorder. American Journal of Orthopsychiatry, 83(1), 115-125.

Loffler-Stastka, H., \& Stigler, K. (2011). [The Affect Experience and Affect Regulation Q-Sort Test (AREQ): validation and short version]. Psychother Psychosom Med Psychol, 61(5), 225-232. doi: 10.1055/s-0030-1263146 Long-Bellil, L. M., Robey, K. L., Graham, C. L., Minihan, P. M., Smeltzer, S. C., \& Kahn, P. (2011). Teaching medical students about disability: the use of standardized patients. Acad Med, 86(9), 1163-1170. doi:

10.1097/ACM.0b013e318226b5dc

Luborsky, L., Crits-Christoph, P., McLellan, A. T., Woody, G., Piper, W., Liberman, B., Pilkonis, P. (1986). Do therapists vary much in their success? Findings from four outcome studies. Am J Orthopsychiatry, 56(4), 501-512. McIntyre, S. M., \& Schwartz, R. C. (1998). Therapists' differential countertransference reactions toward clients with major depression or borderline personality disorder. Journal of Clinical Psychology, 54(7), 923931.

Nissen-Lie, H. A., Monsen, J. T., \& Ronnestad, M. H. (2010). Therapist predictors of early patient-rated working alliance: a multilevel approach. Psychother Res, 20(6), 627-646. doi: 10.1080/10503307.2010.497633 Nissen-Lie, H. A., Monsen, J. T., Ulleberg, P., \& Rønnestad, M. H. (2013). Psychotherapists' self-reports of their interpersonal functioning and difficulties in practice as predictors of patient outcome. Psychotherapy Research, 23(1), 86-104.

Orlinsky, David E, \& Rønnestad, M Helge. (2005). How psychotherapists develop: A study of therapeutic work and professional development. Washington DC: American Psychological Association.

Pascual-Leone, A., Rodriguez-Rubio, B., \& Metler, S. (2013). What else are psychotherapy trainees learning? A qualitative model of students' personal experiences based on two populations. Psychother Res, 23(5), 578-591. doi: 10.1080/10503307.2013.807379 
Rønnestad, M. H., \& Ladany, Nicholas. (2006). The impact of psychotherapy training: Introduction to the special section. Psychotherapy Research, 16(3), 261-267. doi: 10.1080/10503300600612241

Rossberg, J. I., Karterud, S., Pedersen, G., \& Friis, S. (2007). An empirical study of countertransference reactions toward patients with personality disorders. Compr Psychiatry, 48(3), 225-230. doi:

10.1016/j.comppsych.2007.02.002

Salzer, S., Streeck, U., Jaeger, U., Masuhr, O., Warwas, J., Leichsenring, F., \& Leibing, E. (2013). Patterns of interpersonal problems in borderline personality disorder. Journal of Nervous and Mental Disease, 201(2), 94-98. Sandell, R., Carlsson, J., Schubert, J., Broberg, J., Lazar, A., \& Grant, J. (2004). Therapist attitudes and patient outcomes: I. Development and validation of the Therapeutic Attitudes Scales (TASC-2). Psychotherapy Research, 14(4), 469-484. doi: 10.1093/ptr/kph039

Sandell, R., Lazar, Anna, Grant, Johan, Carlsson, Jan, Schubert, Johan, \& Broberg, Jeanette. (2006). Therapist attitudes and patient outcomes. III. A latent class analysis of therapists. Psychology and Psychotherapy: Theory, Research and Practice, 79(4), 629-647. doi: 10.1348/147608306x105694 Sandell, Rolf, Lazar, Anna, Grant, Johan, Carlsson, Jan, Schubert, Johan, \& Broberg, Jeanette. (2007). Therapist attitudes and patient outcomes: II. Therapist attitudes influence change during treatment. Psychotherapy Research, 17(2), 196-204. doi: 10.1080/10503300600608439

Schwartz, R. C., Smith, S. D., \& Chopko, B. (2007). Psychotherapists' countertransference reactions toward lients with Antisocial Personality Disorder and Schizophrenia: An empirical test of theory. American Journal of Psychotherapy, 61(4), 375-393.

Shaw, B. F., Elkin, I., Yamaguchi, J., Olmsted, M., Vallis, T. M., Dobson, K. S., Imber, S. D. (1999). Therapist competence ratings in relation to clinical outcome in cognitive therapy of depression. J Consult Clin Psychol, 67(6), 837-846.

Taubner, S., Kächele, H., Visbeck, A., Rapp, A., \& Sandell, R. (2010). Therapeutic attitudes and practice patterns among psychotherapy trainees in Germany. European Journal of Psychotherapy and Counselling, 12(4), 361381.

Weaver, M., \& Erby, L. (2012). Standardized patients: a promising tool for health education and health promotion. Health Promot Pract, 13(2), 169174. doi: $10.1177 / 1524839911432006$

Westen, D., Muderrisoglu, S., Fowler, C., Shedler, J., \& Koren, D. (1997). Affect regulation and affective experience: individual differences, group differences, and measurement using a Q-sort procedure. J Consult Clin Psychol, 65(3), 429-439.

Winnicott, Donald Woods. (1989). Holding and interpretation: Fragment of 
an analysis: Grove Press.

Zittel, C, \& Westen, D. (2003). The countertransference questionnaire. Atlanta, GA: Departments of Psychology and Psychiatry and Behavioral Sciences, Emory University. 